\title{
COMPARISON OF DRY ASHING, WET ASHING AND MICROWAVE DIGESTION FOR DETERMINATION OF TRACE ELEMENTS IN PERIOSTRACUM SERPENTIS AND PERIOSTRACUM CICADAE BY ICP-AES
}

\author{
LI YANG ${ }^{1,3}$, YANLAN LI', GUOXJ XJ ${ }^{3}, X I A O Q I N M A^{1}$, QINGHUA YAN²* \\ ${ }^{1}$ Department of Experimental Center, Henan Institute of Science and Technology, Xinxiang Henan 453003, China \\ ${ }^{2}$ Department of Life Science and Technology, Xinxiang Medical University, Xinxiang Henan 453003, China \\ ${ }^{3}$ School of Environmont, Henan Normal University, Key Laboratory for Yellow River and Huai River Water Environment and Pollution Control, Ministry of \\ Education. Henan Key Laboratory for Environmental Pollution Control, Xinxiang, Henan 453007, P.R. China
}

(Received: November 19, 2012 - Accepted: January 28, 2013)

\begin{abstract}
The work was to demonstrate a repaid, precise and accurate determination method for ten trace elements (Al, $\mathrm{Cd}, \mathrm{Cr}, \mathrm{Cu}, \mathrm{Fe}, \mathrm{Mg}, \mathrm{Mn}, \mathrm{Ni}, \mathrm{Se}$ and $\mathrm{Zn}$ ) in periostracum serpentis (PS) and periostracum cicadae (PC) by inductively coupled plasma atomic emission spectrometry (ICP-AES). In order to evaluate the best digestion method, three different sample digestion methods including dry ashing, wet ashing and microwave digestion procedures were compared in this study. Method validation was carried out through the generation of calibration curves with multi-element standard solutions and a standard addition method by using standard reference material (GBW 07604-Poplar leaves). The results revealed the microwave digestion procedures were the best sample digestion method because of dry ashing and wet ashing procedures without any advantages in terms of digestion efficiency than the microwave digestion procedures. Trace element contents in PS and PC samples presented a wide variability from the test results, and ten trace element contents in PC were found to be higher than in PS. Determination of trace elements by ICP-AES after microwave digestion was more sensitive and precise, which can be used for quality control and analysis of pharmacological effect in various ecdyses of some animal samples.
\end{abstract}

Keywords: ICP-AES·trace elements; Sample preparation methods; Periostracum serpentis; Periostracum cicadae.

\section{INTRODUCTION}

Ecdyses of some animals, such as periostracum serpentis (PS) and periostracum cicadae (PC), can be used as medicine and have different medicinal value or even higher than animal itself. PS is the dry skin membrane of elaphe taeniura cope, elaphe carinata (guenther), zaocys dhumnades (cantor) or other colubridae animals, has the effect of dispelling wind, anticonvulsant, relieving internal fever and removing nebula, can be used to treat hiccup, furuncle, herpes zoster, epidemic parotiditis, febrile convulsion, pharyngitis and skin itch, PC is the larva slough of cryptotympana pustulata fabricius (black cicada), has the effect of dispersing wind-heat, relieving throat sore, promoting eruption, improving eyesight and relieving spasm, can be used to treat anemopyretic cold, pharyngalgia, cough, asthma, measles without adequate eruption, rubella, convulsion and tetanus ${ }^{1}$. Recent pharmacological studies have shown that PC also has antioxidant, anti-inflammatory, sedative and hypothermic effects ${ }^{2,3}$.

Previous studies on the pharmacological effect of natural medicines focused on organic ingredients. With the development of medical science and the deepening of pharmacology study, the relationship between major or trace elements in natural medicines and pharmacological effect become a new research focus, the analysis of elements and elemental speciation has been more common reported ${ }^{4-7}$. At the same time, heavy metal pollution in natural medicines has been causing widespread concern ${ }^{8-12}$. Measuring and controlling the contents of heavy metals in natural medicines have practical significance to evaluate the potential human health risks and promote better use of natural medicines.

Sample pre-treatment appears to be a key step prior to analysis trace elements of natural medicines. In order to eliminate matrix effects and other interference factors, it is necessary to select and optimize digestion method to digest organic materials and convert the analyte into a suitable form for determination. Dry ashing, wet ashing and microwave digestion procedures are commonly used for sample preparation ${ }^{13-16}$. Dry ashing digestion procedures use a high temperature muffle furnace capable of maintaining temperatures of between 200 and $600{ }^{\circ} \mathrm{C}$ to removal the organic matrix in samples, then the residues are dissolved with appropriate solvent. Dry ashing digestion procedures need little reagents and have low blank value, but it may lead some elements volatilize or react with vessel so that get a low recovery rate. Wet digestion procedures can be carried out by adding strong oxidizing acids into sample and heating so that the organic materials in sample can be decomposed. Biological samples, which contain large amounts of organic materials, usually use mixed acid such as $\mathrm{HNO}_{3}-\mathrm{HClO}_{4}, \mathrm{HNO}_{3}-\mathrm{H}_{2} \mathrm{SO}_{4}, \mathrm{HNO}_{3}-\mathrm{HCl}$ and $\mathrm{HNO}_{3}$ $\mathrm{H}_{2} \mathrm{O}_{2}$ to digest ${ }^{17,18}$. Wet ashing digestion procedures are easy to operate and can digest relatively large number of samples, but it consumes a lot of acid which may introduce interferences and can cause environmental pollution. Microwave digestion procedures are a method of heating samples and digestion solution (various acids) in a closed container using microwave, the application of microwave enhances chemistry for sample prepatation and allows for shorter reaction times, reduction in the number of discrete sample prepatation steps, greater sample homogeneity after digestion, increased sample throughput and better precision. The processes are also very well suited for standardization and automation during method development. However, high-pressure, high temperature and acid vapor bring the security issues.

The purpose of the present study was to determine the concentration levels of trace elements in PS and PC samples. The performances of digestion procedures, namely, dry ashing, wet ashing and microwave digestion procedures were compared in this experiment. Microwave digestion procedures as a method of sample preparation were applied to determine of a range of trace elements in PS and PC samples by ICP-AES. The reliability of the method for estimation of trace elements in samples has been checked by analyzing certified reference and standard addition experiment. This paper established a rapid, precise and accurate method to determine trace elements in various ecdyses of some animals samples for their medicine quality control and analysis of pharmacological effect.

\section{EXPERIMENTAL}

\subsection{Apparatus}

The ICP-AES measurements were performed using a Perkin Elmer Optima 2100 DV inductively coupled plasma atomic emission spectrometer (Perkin Elmer Corp., Shelton, Connecticut, USA), equipped with a dual-view plasma torch, a cross-flow nebulizer, a GAST air compressor and WinLab32 software. The optimum instrumental settings and operating conditions are summarized in Table 1.

Table 1. ICP-AES operating conditions.

\begin{tabular}{|c|c|}
\hline RF (MHz) & 40.68 \\
\hline RF power (W) & 1300 \\
\hline Gas flow rate (/min) & \\
\hline Plasma gas & 15.0 \\
\hline Auxiliary gas & 0.2 \\
\hline Nebulizer gas & 0.8 \\
\hline Sample uptake rate (ml/min) & 1.5 \\
\hline Observation height (mm) & 15 \\
\hline Plasma viewing & Radial \\
\hline Read time (s) & 15 \\
\hline Delay time (s) & 30 \\
\hline Wash time (s) & 30 \\
\hline
\end{tabular}


The microwave digestion procedures were performed with a CEM MARS5 closed vessel acid digestion system (CEM, Matthews, NC, USA), equipped with MARS Xpress PTFE advanced composite vessels (internal volume of 55 $\mathrm{mL}$, maximum operating temperature of $300^{\circ} \mathrm{C}$ ).

2.2 Reagents and chemicals

$\mathrm{HNO}_{3}, \mathrm{H}_{2} \mathrm{O}_{2}, \mathrm{KH}_{2} \mathrm{PO}_{4}$ and $\mathrm{H}_{2} \mathrm{SO}_{4}$ are analytical grade. All aqueous solutions and dilutions were prepared with ultrapure water $(18.2 \mathrm{M} \Omega \mathrm{cm})$ obtained from an SG Ultra Clear UV Plus system (Wasseraufbereitung und Regenerierstation $\mathrm{GmbH}$, Germany). Standard solutions of $\mathrm{Al}, \mathrm{Cd}, \mathrm{Cr}, \mathrm{Cu}, \mathrm{Fe}$, $\mathrm{Mg}, \mathrm{Mn}, \mathrm{Ni}, \mathrm{Se}$ and $\mathrm{Zn}(0.00,0.50,1.00,2.00,4.00,8.00 \mathrm{mg} / \mathrm{L})$ were prepared by diluting of ICP-AES multi-element standard stock solution of $1000 \mathrm{mg} / \mathrm{L}$ of 23 elements (Merck, Darmstadt, Germany), standard solution of P $(0.00,5.00$, $10.00,15.00,20.00,25.00 \mathrm{mg} / \mathrm{L}$ ) were prepared by diluting of $50 \mathrm{mg} / \mathrm{L}$ stock standard solutions $\left(0.2195 \mathrm{~g}\right.$ of dried $\mathrm{KH}_{2} \mathrm{PO}_{4}$ in $1000 \mathrm{~mL}$ volumetric flask with ultrapure water). All glass-ware was cleaned by soaking in $15 \%(\mathrm{v} / \mathrm{v}) \mathrm{HNO}_{3}$ for $24 \mathrm{~h}$ and rinsed with ultrapure water prior to use. High purity argon (99.99\%) was used as a plasma sustaining gas.

\subsection{Sample collection}

PS and PC samples were supplied from retail pharmacies located in Xinxiang city, soaked and rinsed repeatedly with tap water, and then rinsed three times (each time for $3 \mathrm{~min}$ ) with ultra-pure water in an ultrasonic cleaner, then placed in constant temperature oven drying at $80{ }^{\circ} \mathrm{C}$ to constant weight. The dried samples were homogenized using an agate homogenizer and stored in polyethylene bottles until analysis.

\subsection{Digestion procedures}

\subsubsection{Dry Ashing}

$0.2000 \mathrm{~g}$ of dried samples (PS and PC) was accurately weighed into a porcelain crucible, the porcelain crucible was then heated in muffle furnace at $200{ }^{\circ} \mathrm{C}$ for $1.5 \mathrm{~h}$, and gradually heated to $350{ }^{\circ} \mathrm{C}$ for $4 \mathrm{~h}$ in order to make the sample dry ashing. The ashed samples were digested with $10 \mathrm{ml}$ of concentrated mixed acid ( $\left.\mathrm{HCl}: \mathrm{HNO}_{3}=1: 1\right)$, then the digestion solution was heated up on electric hot plate at $150^{\circ} \mathrm{C}$ until evaporated to near dryness. The residue was filtered and transferred into a volumetric flask and made up to $25 \mathrm{ml}$ with $3 \%$ $\mathrm{HNO}_{3}$. The blank digestion experiments were also carried out in the same way.

\subsubsection{Wet Ashing}

Recent studies have shown that mixtures of $\mathrm{HNO}_{3} / \mathrm{H}_{2} \mathrm{O}_{2}$ are better than $\mathrm{HNO}_{3}, \mathrm{HCl}$, or $\mathrm{H}_{2} \mathrm{SO}_{4}$ in terms of complete dissolution in a short time period for wet digestion. That was why the mixtures of $\mathrm{HNO}_{3} / \mathrm{H}_{2} \mathrm{O}_{2}$ were used in the wet digestion procedures. $0.2000 \mathrm{~g}$ of dried samples (PS and PC) was accurately weighed into $50 \mathrm{~mL}$ beaker, added $20 \mathrm{~mL}$ of concentrated $\mathrm{HNO}_{3}$ and $6 \mathrm{~mL}$ of $30 \% \mathrm{H}_{2} \mathrm{O}_{2}$, and then heated up on electric hot plate at $120{ }^{\circ} \mathrm{C}$. After the disappearance of brown fumes, the digestion solution was heated up on electric hot plate at $150{ }^{\circ} \mathrm{C}$ until evaporated to near dryness. The residue was filtered and transferred into a volumetric flask and made up to $25 \mathrm{~mL}$ with $3 \%$ $\mathrm{HNO}_{3}$. The blank digestion experiments were also carried out in the same way.

\subsubsection{Microwave Digestion}

At the beginning, $0.2000 \mathrm{~g}$ of dried sample powder (PS and PC) was accurately weighed into PTFE vessel, then $12 \mathrm{~mL}$ of concentrated $\mathrm{HNO}_{3}$ and 2 $\mathrm{mL}$ of $30 \% \mathrm{H}_{2} \mathrm{O}_{2}$ were poured into PTFE vessel. The vessel was closed, placed on the rotating turntable of the microwave oven and then digestion procedure was started according to the instruction information shown in Table 2. When the digestion program finished, a twenty-minute ventilation step (no microwave power) cooled the vessels for reducing the pressure inside to ambient values. After digestion in microwave, the digestion solution was evaporated to dryness on electric hot plate at $150{ }^{\circ} \mathrm{C}$. The residue was transferred into a volumetric flask and made up to $25 \mathrm{~mL}$ with $3 \% \mathrm{HNO}_{3}$. Blank test was carried out in the same way.

Table 2. The program of microwave digestion

\begin{tabular}{|c|c|c|c|c|}
\hline Stage & $\begin{array}{c}\text { Power } \\
\mathrm{P}(\mathrm{W})\end{array}$ & $\begin{array}{c}\text { Heating-up } \\
\text { time } \\
\mathrm{t}(\mathrm{min})\end{array}$ & $\begin{array}{c}\text { Operating } \\
\text { temperature } \\
\mathrm{T}\left({ }^{\circ} \mathrm{C}\right)\end{array}$ & $\begin{array}{c}\text { Operating } \\
\text { time } \\
\mathrm{t}(\mathrm{min})\end{array}$ \\
\hline 1 & 760 & 5 & 120 & 3 \\
\hline 2 & 760 & 3 & 150 & 3 \\
\hline 3 & 760 & 5 & 150 & 15 \\
\hline
\end{tabular}

\section{RESULTS AND DISCUSSION}

3.1 Spectral Lines, Standard Curves and Detection Limits

ICP-AES can select a number of characteristic spectral lines for determination of each element, and spectrometer has the function of a synchronized automatic background correction. In the experiment, 2-3 characteristic lines were selected to determine for each element, the possible disturbance factors were discussed, and the spectral lines of less spectral interference, high signal to noise ratio and precision were chosen. Spectral lines optimized are shown in Table 3.

Standard solutions were determined to obtain the standard curves of each element under optimized conditions. The linear correlation coefficients of standard curves were in the range of 0.999707 - 0.999999, which shows a good liner relationship between the concentration and absorbance of each element.

The detection limits are defined as the concentrations corresponding to three times the standard deviation of eleven blanks. The results are shown in Table 3.

Table 3. Analytical spectral lines and detection limits of the trace elements

\begin{tabular}{|c|c|c|c|c|}
\hline Element & $\begin{array}{c}\text { Spectral } \\
\text { line } \\
\lambda(\mathrm{nm})\end{array}$ & Regression equation & $\begin{array}{c}\text { Correlation } \\
\text { coefficient } \\
\left(\mathrm{r}^{2}\right)\end{array}$ & $\begin{array}{c}\text { Detection } \\
\text { limit } \\
(\mu \mathrm{g} / \mathrm{mL})\end{array}$ \\
\hline $\mathrm{Al}$ & 396.153 & $\mathrm{Y}=196900 \mathrm{X}-1479.9$ & 0.999998 & 0.030 \\
\hline $\mathrm{Cd}$ & 226.502 & $\mathrm{Y}=111700 \mathrm{X}+7596.2$ & 0.999858 & 0.005 \\
\hline $\mathrm{Cr}$ & 267.716 & $\mathrm{Y}=117100 \mathrm{X}+541.8$ & 0.999999 & 0.009 \\
\hline $\mathrm{Cu}$ & 324.752 & $\mathrm{Y}=409000 \mathrm{X}+9950.4$ & 0.999982 & 0.007 \\
\hline $\mathrm{Fe}$ & 259.939 & $\mathrm{Y}=178400 \mathrm{X}-1273.2$ & 0.999998 & 0.080 \\
\hline $\mathrm{Mg}$ & 279.077 & $\mathrm{Y}=15930 \mathrm{X}+512.7$ & 0.999968 & 0.050 \\
\hline $\mathrm{Mn}$ & 257.610 & $\mathrm{Y}=1096000 \mathrm{X}+13532$ & 0.999995 & 0.002 \\
\hline $\mathrm{Ni}$ & 231.604 & $\mathrm{Y}=49540 \mathrm{X}-27.3$ & 0.999999 & 0.002 \\
\hline $\mathrm{Se}$ & 196.026 & $\mathrm{Y}=4842 \mathrm{X}+52.8$ & 0.999707 & 0.095 \\
\hline $\mathrm{Zn}$ & 213.857 & $\mathrm{Y}=116600 \mathrm{X}+6631.7$ & 0.999901 & 0.002 \\
\hline
\end{tabular}

\subsection{Analysis of Standard Reference Material}

In order to verify the accuracy of the digestion procedures, a certified reference material GBW 07604-Poplar leaves (China National Research Center for Certified Reference Materials) was used. For dry ashing, wet ashing and microwave digestion procedures, $1.0000 \mathrm{~g}$ certified reference material was used, the standard reference material was treated according to the corresponding sample processing method as described above, respectively. As it could be seen, microwave digestion procedures were successful for the digestion of standard reference material, the results were found to be in good agreement with the certified values as in Table 4 . The relative standard deviation for three digestion replicates of each sample was in the range from $0.15 \%$ to $4.87 \%$.

Table 4. Results of trace element contents of GBW 07604- poplar leaves certified reference material determined after dry ashing, wet ashing and microwave digestion procedures $(\mathrm{mg} / \mathrm{kg}),(\mathrm{n}=5)$.

\begin{tabular}{|c|c|c|c|c|}
\hline Element & $\begin{array}{c}\text { Certified } \\
\text { value }\end{array}$ & $\begin{array}{c}\text { Microwave } \\
\text { digestion }\end{array}$ & $\begin{array}{c}\text { Wet } \\
\text { ashing }\end{array}$ & Dry ashing $^{\mathrm{a}}$ \\
\hline $\mathrm{Al}$ & $1.04 \times 10^{3}$ & $1.02 \times 10^{3} \pm 3.34$ & $\begin{array}{c}1.01 \times 10^{3} \pm \\
4.76\end{array}$ & $1.00 \times 10^{3} \pm 5.04$ \\
\hline $\mathrm{Cd}$ & 0.32 & $0.31 \pm 0.86$ & $0.29 \pm 1.74$ & $0.41 \pm 3.91$ \\
\hline $\mathrm{Cr}$ & 0.55 & $0.58 \pm 1.03$ & $0.62 \pm 2.42$ & $0.67 \pm 4.71$ \\
\hline $\mathrm{Cu}$ & 9.30 & $9.35 \pm 2.22$ & $9.42 \pm 3.18$ & $9.45 \pm 3.73$ \\
\hline $\mathrm{Fe}$ & $2.74 \times 10^{2}$ & $\begin{array}{c}2.71 \times 10^{2} \pm \\
1.22\end{array}$ & $\begin{array}{c}2.68 \times 10^{2} \pm \\
2.51\end{array}$ & $\begin{array}{c}2.89 \times 10^{2} \pm \\
4.24\end{array}$ \\
\hline $\mathrm{Mg}$ & 0.65 & $0.64 \pm 1.08$ & $0.71 \pm 2.23$ & $0.74 \pm 3.82$ \\
\hline $\mathrm{Mn}$ & 45 & $44.7 \pm 0.99$ & $44.0 \pm 1.95$ & $43.3 \pm 3.48$ \\
\hline $\mathrm{Ni}$ & 1.9 & $1.88 \pm 1.42$ & $1.75 \pm 2.80$ & $2.23 \pm 3.97$ \\
\hline $\mathrm{Se}$ & 0.14 & $0.13 \pm 2.34$ & $0.17 \pm 2.95$ & $0.18 \pm 4.31$ \\
\hline $\mathrm{Zn}$ & 37 & $36.6 \pm 2.53$ & $38.5 \pm 4.19$ & $39.0 \pm 3.47$ \\
\hline
\end{tabular}

${ }^{\text {a }}$ Mean \pm standard deviation. 
3.3 The Results of Sample Analysis

The determination results of the trace elements $(\mathrm{Al}, \mathrm{Cd}, \mathrm{Cr}, \mathrm{Cu}, \mathrm{Fe}, \mathrm{Mg}$, $\mathrm{Mn}, \mathrm{Ni}, \mathrm{Se}$ and $\mathrm{Zn}$ ) of PS and PC samples using different digestion procedures are presented in Table 5. It was observed that the element contents in PS and PC samples presented a wide variability from the test results, and the trace elements contents in PC were found to be higher than in the PS. Al, Fe, Mg, Mn contents in PC were about one or two orders of magnitude the level than in PS. $\mathrm{Cd}, \mathrm{Cr}, \mathrm{Cu}, \mathrm{Ni}$ and $\mathrm{Zn}$ concentrations in both samples indicated similar maximum levels, they were determined in the range of $2.14-2.51 \mathrm{mg} / \mathrm{kg}, 2.58$ $2.89 \mathrm{mg} / \mathrm{kg}, 11.7-14.4 \mathrm{mg} / \mathrm{kg}, 2.10-4.58 \mathrm{mg} / \mathrm{kg}$ and $1.28 \times 10^{2}-1.93 \times 10^{2} \mathrm{mg} /$ $\mathrm{kg}$, respectively. Se content in PS was relatively higher than in PC. The trace element composition of PS and PC samples changes greatly for varied reasons, such as nutritional value, toxicity, pollution, geographic origin of plants, etc. On the other hand, the presence of trace elements in PS and PC are of particular concern for more specifically living organisms themselves and their growing environment.

Table 5. Results of trace element contents in PS and PC samples determined after dry ashing, wet ashing and microwave digestion procedures $(\mathrm{mg} / \mathrm{kg}),(\mathrm{n}=5)$

\begin{tabular}{|c|c|c|c|c|c|c|}
\hline Element & \multicolumn{2}{|c|}{ Periostracum serpentis } & \multicolumn{3}{c|}{ Periostracum cicadae } \\
\hline & $\begin{array}{c}\text { Microwave acid- } \\
\text { digestion }\end{array}$ & Wet digestion & $\begin{array}{c}\text { Dry ashing } \\
\text { digestion }\end{array}$ & $\begin{array}{c}\text { Microwave acid- } \\
\text { digestion }\end{array}$ & Wet digestion & $\begin{array}{c}\text { Dry ashing } \\
\text { digestion }\end{array}$ \\
\hline $\mathrm{Al}$ & $1.74 \times 10^{2}$ & $1.72 \times 10^{2}$ & $1.50 \times 10^{2}$ & $2.12 \times 10^{3}$ & $1.98 \times 10^{3}$ & $1.83 \times 10^{3}$ \\
\hline $\mathrm{Cd}$ & 2.14 & 1.98 & 1.87 & 2.51 & 2.33 & 2.20 \\
\hline $\mathrm{Cr}$ & 2.58 & 2.51 & 2.25 & 2.89 & 2.81 & 2.52 \\
\hline $\mathrm{Cu}$ & 11.7 & 10.1 & 8.49 & 14.4 & 12.9 & 11.1 \\
\hline $\mathrm{Fe}$ & $4.72 \times 10^{2}$ & $3.78 \times 10^{2}$ & $3.64 \times 10^{2}$ & $3.00 \times 10^{3}$ & $2.40 \times 10^{3}$ & $2.31 \times 10^{3}$ \\
\hline $\mathrm{Mg}$ & $2.40 \times 10^{2}$ & $1.63 \times 10^{2}$ & $1.03 \times 10^{2}$ & $2.14 \times 10^{3}$ & $1.79 \times 10^{3}$ & $1.57 \times 10^{3}$ \\
\hline $\mathrm{Mn}$ & 6.19 & 5.28 & 5.16 & $4.83 \times 10^{2}$ & $4.95 \times 10^{2}$ & $4.54 \times 10^{2}$ \\
\hline $\mathrm{Ni}$ & 2.10 & 1.24 & 0.91 & 4.58 & 2.34 & 1.95 \\
\hline $\mathrm{Se}$ & 10.4 & 8.54 & 2.60 & 7.43 & 6.09 & 1.85 \\
\hline $\mathrm{Zn}$ & $1.28 \times 10^{2}$ & $1.21 \times 10^{2}$ & $1.18 \times 10^{2}$ & $1.93 \times 10^{2}$ & $1.84 \times 10^{2}$ & $1.78 \times 10^{2}$ \\
\hline
\end{tabular}

\subsection{Method Validation}

In order to demonstrate the validity of the proposed method, the accuracy and recovery test were carried out. The accuracy was evaluated by means of repeatability measures of samples. Table 6 shows these data with the validation parameters of ICP-AES methods. It was evident that the proposed method was more sensitive and precise. The recovery tests were performed by measuring the PS and PC spiked samples. The average recoveries were $93.3-1.03 \times 10^{20} \%$ (RSDs $<6.87 \%$ ) for PS sample, $92.8-1.07 \times 10^{20} \%$ for PC sample (RSDs $<$ $8.24 \%$ ) respectively. If the analyzed concentration levels of the most common matrix constituents of certified reference materials and the accuracy of the presented methods were considered together, it could be concluded that the proposed method was accurate and precise.

Table 6. Results of the accuracy and recovery tests by measuring the PS and PC spiked samples (n=5).

\begin{tabular}{|c|c|c|c|c|c|c|c|c|c|c|}
\hline Element & \multicolumn{9}{|c|}{ Periostracum serpentis } & \multicolumn{4}{|c|}{ Periostracum cicadae } \\
\hline & $\begin{array}{c}\text { Blank } \\
(\mathrm{mg} / \mathrm{L})\end{array}$ & $\begin{array}{c}\text { Added } \\
(\mathrm{mg} / \mathrm{L})\end{array}$ & $\begin{array}{c}\text { Detected } \\
(\mathrm{mg} / \mathrm{L})\end{array}$ & $\begin{array}{c}\text { Recovery } \\
(\%)\end{array}$ & $\begin{array}{c}\text { RSD } \\
(\%)\end{array}$ & $\begin{array}{c}\text { Blank } \\
(\mathrm{mg} / \mathrm{L})\end{array}$ & $\begin{array}{c}\text { Added } \\
(\mathrm{mg} / \mathrm{L})\end{array}$ & $\begin{array}{c}\text { Detected } \\
(\mathrm{mg} / \mathrm{L})\end{array}$ & $\begin{array}{c}\text { Recovery } \\
(\%)\end{array}$ & $\begin{array}{c}\text { RSD } \\
(\%)\end{array}$ \\
\hline $\mathrm{Al}$ & $1.74 \times 10^{2}$ & 50 & $2.22 \times 10^{2}$ & 96.8 & 5.12 & $2.12 \times 10^{3}$ & 100 & $2.22 \times 10^{3}$ & 94.3 & 4.86 \\
\hline $\mathrm{Cd}$ & 2.14 & 2 & 4.11 & 98.7 & 3.21 & 2.51 & 2 & 4.46 & 97.62 & 1.95 \\
\hline $\mathrm{Cr}$ & 2.58 & 2 & 4.63 & $1.02 \times 10^{2}$ & 2.26 & 2.89 & 2 & 4.95 & $1.02 \times 10^{2}$ & 2.37 \\
\hline $\mathrm{Cu}$ & 11.7 & 10 & 22 & $1.03 \times 10^{2}$ & 3.24 & 14.4 & 15 & 30.1 & $1.04 \times 10^{2}$ & 2.15 \\
\hline $\mathrm{Fe}$ & $4.72 \times 10^{2}$ & 100 & $5.67 \times 10^{2}$ & 94.6 & 1.86 & $3.00 \times 10^{3}$ & 100 & $3.11 \times 10^{3}$ & $1.07 \times 10^{2}$ & 1.67 \\
\hline $\mathrm{Mg}$ & $2.39 \times 10^{2}$ & 100 & $3.37 \times 10^{2}$ & 97.6 & 3.18 & $2.14 \times 10^{2}$ & 100 & $2.24 \times 10^{2}$ & $1.05 \times 10^{2}$ & 2.60 \\
\hline $\mathrm{Mn}$ & 6.19 & 5 & 11.1 & 98.9 & 1.34 & $4.83 \times 10^{2}$ & 100 & $5.85 \times 10^{2}$ & $1.02 \times 10^{2}$ & 1.52 \\
\hline $\mathrm{Ni}$ & 2.10 & 2 & 4.04 & 97.1 & 2.62 & 4.58 & 5 & 9.51 & 98.5 & 3.59 \\
\hline $\mathrm{Se}$ & 10.4 & 10 & 19.7 & 93.3 & 6.87 & 7.43 & 5 & 12.2 & 94.8 & 8.24 \\
\hline $\mathrm{Zn}$ & $1.28 \times 10^{2}$ & 100 & $2.23 \times 10^{2}$ & $9.57 \times 10^{2}$ & 3.24 & $1.93 \times 10^{2}$ & 100 & $2.86 \times 10^{2}$ & 92.8 & 4.21 \\
\hline
\end{tabular}

\section{CONCLUSION}

Microwave digestion procedures offered certain advantages over conventional wet ashing and dry ashing digestion procedures. The dry ashing and wet ashing digestion procedures were more time-consuming and complicated than the microwave digestion procedures without any advantages in terms of digestion efficiency. The use of microwave digestion procedures in PS and PC samples provided a simpler, effective, faster, and less contamination procedure of sample preparation. Moreover, the proposed digestion procedures were more suitable for the contents determination of $\mathrm{Al}, \mathrm{Cd}, \mathrm{Cr}, \mathrm{Cu}, \mathrm{Fe}, \mathrm{Mg}$, $\mathrm{Mn}, \mathrm{Ni}, \mathrm{Se}$ and $\mathrm{Zn}$ in various medicine samples. The results showed that trace element contents in PS and PC samples present a wide variability, and the trace element contents in PC were found to be higher than in PS. The presence of trace elements in PS and PC were of particular concern for more specifically living organisms themselves and their growing environment. It was important to have a good quality control for different PS and PC samples as the medicaments in order to protect consumers from contamination.

\section{REFERENCES}

1. The State Pharmacopoeia Commission of People's Republic of China. Pharmacopoeia of the People's Republic of China. Beijing: Chemical Industry Press, 1, 220, (2005)

2. M. Z. Xu, W. S. Lee, J. M. Han, H. W. Oh, D. S. Park, G. R.Tian, T. S. 
Jeongb, H.Y. Park, Bioorg. Med. Chem. Lett. 14, 7826, (2006)

3. M. T. Hsieh, W. H. Peng, F. T.Yeh, H. Y.Tsai, Y. S. Chang, J. Ethnopharmacol. 35, 83, (1991)

4. X. W. Zhou, Z. H. Gong, Y. Su, J. Lin, K. X. Tang, J. Pharm. Pharmacol. 61, 279, (2009)

5. A. Stocker, P. Schramel, A. Kettrup, E. Bengsch, J. Trace Elem. Med. Bio. 19, 183, (2005)

6. R. Kumar, G. P. Kumar, O. P. Chaurasia, S. B. Singh, Research J. Med. Plant. 5, 491, (2011)

7. K. Y. Khan, M. A. Khan, R. Niamat, M. Munir, H. Fazal, P. Mazari, N. Seema, T. Bashir, A. Kanwal, S. N. Ahmed, Afr. J. Pharm. Pharmaco. 5, 317, (2011)

8. R. Bhat, K. Kiran, A. B. Arun, A. A. Karim, Food Anal. Method. 3, 181, (2010)

9. E. V. Chuparina, T. S.Aisueva, Environ. Chem. Lett. 9, 19, (2011)

10. B. Deo, G. Nahak, R. K. Sahu, J. Am. Sci. 7, 29, (2011)
11. M. R. Gomez, S. Cerutti, L. L. Sombra, M. F. Silva, L. D. Martínez, Food Chem. Toxicol. 45, 1060, (2007)

12. P. Kalny, Z. Fijałek, A. Daszczuk, P. Ostapczuk, Sci. Total Environ. 381, 99, (2007)

13. F. G. Antes, F. A. Duarte, M. F. Mesko, M. A. G. Nunes, V. A. Pereira, E. I. Müller, V. L. Dressler, E. M. M. Flores, Talanta. 83, 364, (2010)

14. K. Nemati, N. K. A. Bakar, M. R. B. Abas, E. Sobhanzadeh, K. H. Low, J. Hazardous Mater. 182, 453, (2010)

15. A. C. Sahayam, S. C. Chaurasia, G. Venkateswarlu, Anal. Chim. Acta. 661, 17, (2010)

16. P. K. Hsiao, S. J. Jiang, A. C. Sahayam, J. Anal. Ato. Spectrom. 26, 586, (2011)

17. D. Bakircioglu, Y. B. Kurtulus, G. Ucar, Food Chem. Toxicol. 49, 202, (2011)

18. S. Demirel, M. Tuzen, S. Saracoglu, M. Soylak, J. Hazardous Mater. 152, 1020. (2008) 